\title{
Anomalous transients in GPS measurements due to induced changes in local site conditions
}

\author{
Sandeep Gupta ${ }^{1}$, Paresh Nath Singharoy ${ }^{2}$, Rajeev Kumar Yadav $^{3}$, Joshi K Catherine ${ }^{4}$, \\ Roland Burgmann $^{5}$ and Vineet K Gahalaut ${ }^{4,6, *} \bullet$ \\ ${ }_{2}^{1}$ Department of Applied Geophysics, Indian School of Mines, Dhanbad 826 004, India. \\ ${ }^{2}$ Department of Geology and Geophysics, Indian Institute of Technology, Kharagpur, India. \\ ${ }^{3}$ Institute of Seismological Research, Raisan, Gandhinagar, India. \\ ${ }_{5}^{4}$ CSIR-National Geophysical Research Institute, Hyderabad, India. \\ ${ }^{5}$ Department of Earth and Planetary Science, University of California, Berkeley, USA. \\ ${ }^{6}$ National Centre for Seismology, Ministry of Earth Sciences, New Delhi, India. \\ *Corresponding author.e-mail:vkgahalaut@yahoo.com
}

MS received 22 January 2019; revised 6 April 2019; accepted 11 April 2019; published online 5 July 2019

Transients in GPS time series can occur due to post-seismic deformation, seasonal hydrological loads, sea-level changes, flood and drought conditions, excessive groundwater withdrawal and recharge, etc. We report two new cases where the application of external loading, namely, earthquake loading and surface loading due to impoundment of hydroelectric reservoir, probably altered the local hydrological conditions to cause anomalous transients in the surface displacement. In the first case, moderate shaking due to the 2015 Gorkha earthquake at Patna (Bihar, India) caused transients in ground deformation in the following 50-60 days of the earthquake which are recorded by a continuous GPS site at Patna. In the second case, impoundment of the Tehri reservoir and its seasonal variations in the Garhwal Himalaya probably altered the local hydrological conditions which is causing anomalous biannual cyclic deformation at a site KUNR, near the reservoir.

Keywords. GPS measurements; crustal deformation; Nepal earthquake; post-seismic deformation.

\section{Introduction}

Local site conditions can influence and enhance the effect of externally applied dynamic and static loading. For example, the damage due to ground shaking is sometimes enhanced due to the poor site condition. The damage to the city of Mexico due to the 1985 Mexico city earthquake, which in fact occurred $\sim 350 \mathrm{~km}$ away from Mexico city, is one such example. Such conditions could be highly localised and, in many cases, could be caused by local hydrological conditions and properties of unconsolidated sediments leading to soil liquefaction, sand boils and ground fissures. Such effects may be seen immediately after the event or they could be prolonged and continued for some days to months. Due to the advent of space-based geodetic measurements, which in this case happen to be continuous GPS measurements, we are able to record such effects in terms of crustal deformation. However, even now reports of such cases are rare due to the limited availability of such measurements, uniqueness of certain sites/cases to report such effects and relative location of sites with respect to the causing factor, both in terms of time and space to record such effects. In this article, we provide two case histories, wherein the effect of 
such loading is evident in GPS measurements. In one case, the effect of an earthquake (ground shaking) at a moderately far-off GPS site is seen in the following 50-60 days of the mainshock. In the other case, the effect of surface loading due to reservoir impoundment on a neighbouring GPS site appears to be different from the expectations based on simple poroelastic modelling.

\section{2015 Gorkha earthquake-induced transients at a GPS site in the Indo-Gangetic plains}

The 2015 Gorkha earthquake not only caused destruction in the Nepal region, but also strongly affected the neighbouring Indian states of Bihar and western Uttar Pradesh. The intensity of the effects of the earthquake in Bihar reached up to six on the EMS-98 scale (Martin et al. 2015; Hough et al. 2016). The earthquake also caused coseismic offsets in the region which were estimated using continuous GPS measurements at Patna (PTNA), Bhagalpur (BHGP), Dhanbad (DHAN) and Ranchi (RANC) (Yadav et al. 2017). Being the closest, site PTNA recorded the maximum offset of $7 \pm 3 \mathrm{~mm}$ towards the north (figure 1a).
We processed GPS measurements of 2015-2017 from these sites (PTNA, BHGP, RANC and an additional site, ARAR which was established two months after the earthquake and a nearby IGS site LCK3, figure 1), along with data from several IGS sites using GAMIT/GLOBK (Herring 2005; King and Bock 2005) to estimate the time series of site coordinates and their mean velocities. Site position estimates and their rates were estimated in ITRF2008 (Altamimi et al. 2011) by stabilising sites in stable continental regions and core IGS reference sites. We removed the Indian plate motion (Ader et al. 2012) from the GPS time series (figure 2). In our case, the choice of the Euler pole does not matter much as here we are not interested in the secular motion but in the transients or the seasonal variations. We analysed the coordinate time series with the aim to see if any far-field postseismic transients, associated with the afterslip and viscous relaxation in the lower crust and upper mantle due to the 2015 Gorkha earthquake, can be resolved (e.g., Zhao et al. 2017). We also removed the effects of hydrological, atmospheric and nontidal loads using mass redistribution models described by the international mass loading service (http://arxiv.org/abs/1503.00191) from all sites, following Gahalaut et al. (2017). LCK3, RANC and

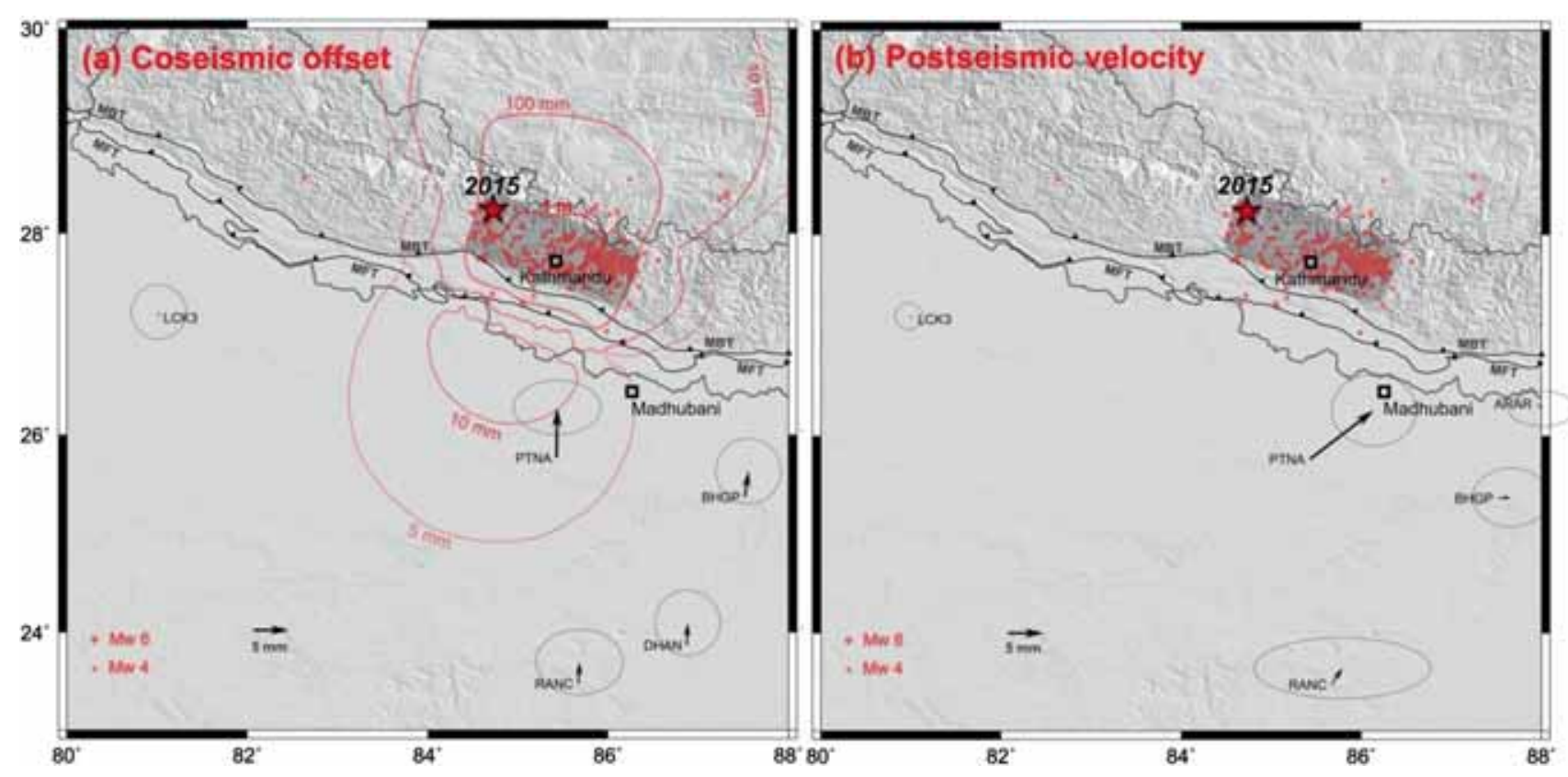

Figure 1. (a) Coseismic offsets at GPS sites due to 2015 Gorkha earthquake (red star). Red solid circles are the aftershocks of the Gorkha earthquake which approximately mark the extent of the rupture (shown by the rectangle). Red contours are the simulated horizontal coseismic offset due to the estimated slip distribution model of 2015 Gorkha earthquake (Yadav et al. 2017). The location of the site in Madhubani district reporting soil liquefaction, ground fissures and sand boils is also shown. (b) Postearthquake velocity at sites in the Indian reference frame. At site PTNA, the movement of 50 days following the earthquake is shown as there is a large variation in the overall velocity at this site. 

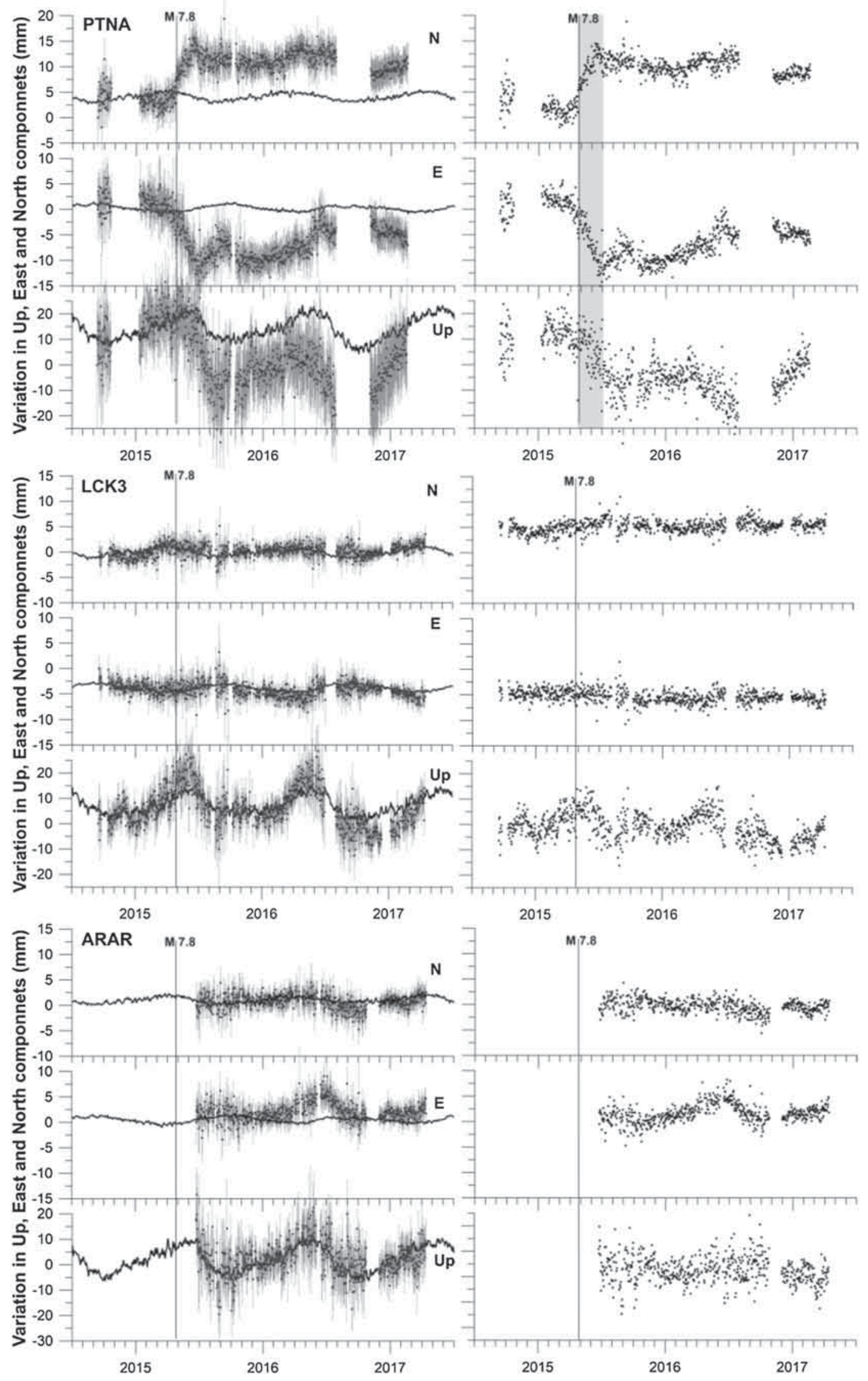

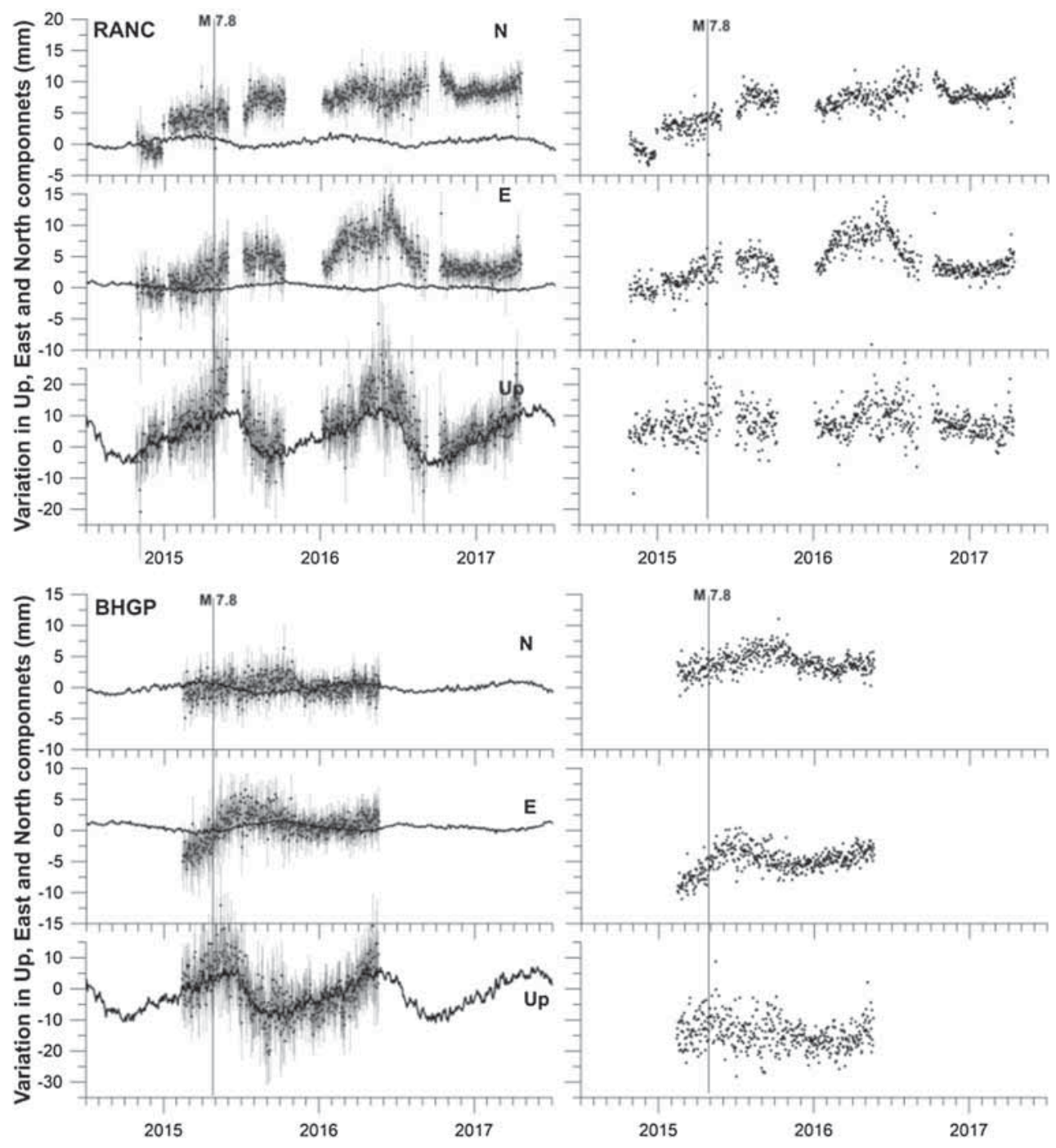

Figure 2. GPS time series at PTNA, LCK3, ARAR, RANC and BHGP GPS sites in the Indo-Gangetic plains south of the 2015 Gorkha earthquake. Left panel for each site shows the N, E and Up components of the GPS time series in the Indian reference frame along with the displacement components derived from the global hydrological model. Right panel in each case shows the residual time series after subtracting the contribution of the hydrological load. Vertical line is the time of the 2015 Gorkha earthquake. Note the strong transient at PTNA after the 2015 Gorkha earthquake.

ARAR do not show any significant transient motion in the 3 yrs following the earthquake (figure 2). However, station PTNA experienced some anomalous transient in the 50-60 days following the earthquake. It slowly moved by about $11 \mathrm{~mm}$ (with daily location error of $4.5 \mathrm{~mm}$ ) towards WNW. The vertical component exhibits relative subsidence of about $15 \mathrm{~mm}$ (with daily location error of $13 \mathrm{~mm}$ ) but due to the large uncertainty in the vertical component and some remnant influence of hydrological loading which could not be taken care of completely in the low resolution global hydrological models, it may not be very reliable. Such transient movements are not seen at any other nearby site, even though some of these sites, e.g., BHGP are located in a similar environment (young alluvial sediments of the Indo-Gangetic plains) but at a larger distance. In fact, BHGP shows some transient movement $(\sim 4 \mathrm{~mm}$ towards east) but it appears to be within the noise level of displacement estimated from GPS measurements and the remnant variations.

Noting that PTNA is located immediately south to the 2015 rupture and is the nearest among the sites analysed here, we also checked whether the transients could be due to post-seismic deformation either due to afterslip, viscoelastic relaxation or poroelastic rebound of the 2015 earthquake. While analysing GPS measurements from the Nepal 
region, Zhao et al. (2017) examined contributions from all processes and indicated that incorporating poroelastic relaxation increases the misfit at sites in Nepal. They indicated a northward velocity of not more than $1 \mathrm{~cm}$ in the following half year of the earthquake in the Indo-Gangetic plains immediately south of the 2015 rupture. At the latitude of PTNA, the maximum contribution from viscoelastic relaxation would be $<0.5 \mathrm{~cm}$ towards the north in $0.5 \mathrm{yr}$ which is inconsistent, both in direction and magnitude with that actually observed at PTNA. Since the transient at PTNA is short lived, a poroelastic relaxation of the coseismic pressure changes from the 2015 Gorkha earthquake could be envisaged as a possible mechanism leading to transient. However, that does not seem to be correct as Zhao et al. (2017) indicated that its contribution would be insignificant at this distance.

We suggest that the observed transient at PTNA may be very localised and it may be due to the change in local hydrological conditions caused by the coseismic ground shaking during the earthquake. We confirmed that the GPS monument at PTNA has not sustained any damage and has not experienced any tilt due to shaking caused by the earthquake. Also, there has been no change in the antenna or receiver since the installation of this and any other sites. The site is located on the alluvium of the Indo-Gangetic plains and is about $6 \mathrm{~km}$ from the right bank of the Ganga river. It is possible that moderate ground shaking in the region due to the earthquake caused some nonlinear localised groundwater flow or soil liquefaction which led to permanent deformation near the site, although the transient settled down in the following 50-60 days. Although there are no reports of soil liquefaction, ground fissures or sand boils in the neighbourhood of the GPS site at PTNA, Geological Survey of India reported evidence of soil liquefaction, ground fissures and sand boils from the Madhubani district (figure 1, http://www. portal.gsi.gov.in/gsiDoc/pub/nepaleq_\%20liq.pdf, also cited by Rajendran et al. 2016). Both Patna and Madhubani are located in the Indo-Gangetic plains along the Ganga and Kamla rivers, respectively. While Patna is located immediate south of the 2015 earthquake rupture at a distance of $230 \mathrm{~km}$ from Kathmandu, Madhubani is located $170 \mathrm{~km}$ southeast of Kathmandu. In fact, looking at the simulated coseismic displacement due to the 2015 Gorkha earthquake (figure 3 of Yadav et al. 2017), it appears that both places experienced similar coseismic offset (figure 1), although the distance of Madhubani is less than that of Patna from the earthquake rupture. As the geological and ground water conditions are similar at both places which experienced similar ground shaking due to the earthquake (Martin et al. 2015), and there are unequivocal evidence of soil liquefaction, ground fissures and sand boils from one of two sites, Madhubani district, we surmise that similar effects might have occurred in the neighbourhood of the PTNA site, though at a much lesser scale to be visible at the surface but enough to be recorded at the PTNA GPS site.

\section{Tehri reservoir loading effect at a GPS site in Garhwal Himalaya}

Gahalaut et al. (2017) reported transients in the GPS measurements at station KUNR, which is located less than $1 \mathrm{~km}$ from the Tehri reservoir on a massive outcrop of phillites of the Lesser Himalaya of the Garhwal region. The reported secular motion (of $\sim 0.5 \mathrm{~mm} / \mathrm{yr}$ in the Indian reference frame) at this site is consistent with the underlying locked main Himalayan thrust (Yadav et al. 2019). Gahalaut et al. (2017) reported that the transient deformation at the site is influenced by the reservoir filling and emptying cycles. They removed the influence of hydrological, atmospheric and nontidal ocean loads from the GPS time series. The variations in the $\mathrm{N}$ and $\mathrm{Up}$ components of residual GPS time series show a good correspondence with the simulated displacement due to reservoir filling and emptying cycles (figure 3). However, the E component exhibits some anomalous behaviour. Rather than showing annual variations as seen in the simulated reservoir load due to annual filling and emptying cycles of the reservoir (as also seen in the Up component), variations in the E component are biannual. Even the raw GPS time series shows very prominent biannual variations. There could be two reasons for such biannual variations. First, there is actually a larger spatial variability in the hydrological load than is captured by the global hydrological models and the hydrological loading at KUNR is quite different from that at other nearby sites (e.g., KHIR and GUTU with $<60 \mathrm{~km}$ from KUNR) where the reservoir effect is insignificant. The change in the hydrological condition could itself be due to reservoir loading. Second, the available resolution of global hydrological models is reasonable but at KUNR, the 


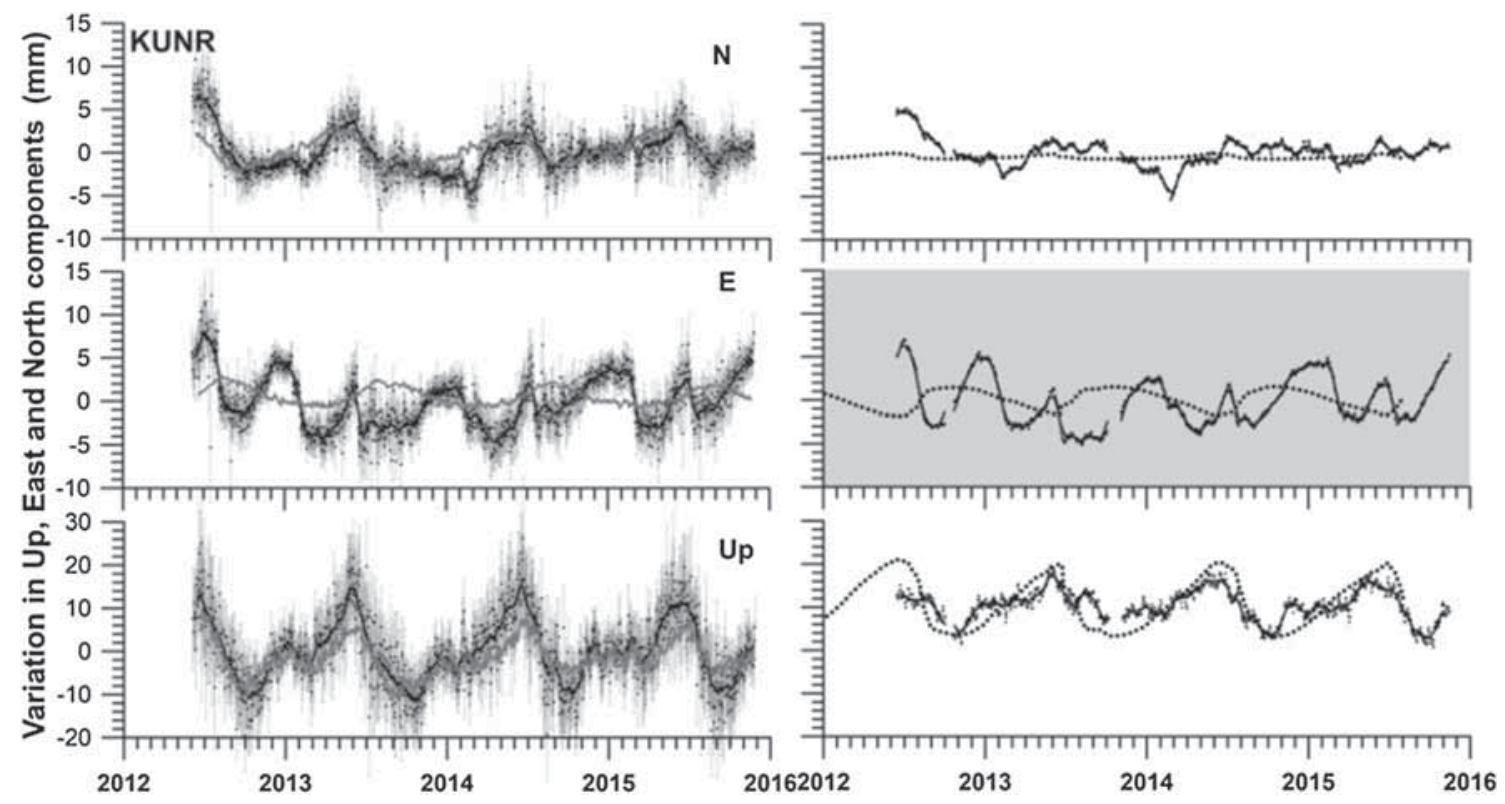

Figure 3. GPS time series at KUNR near the Tehri reservoir. Left panel shows the N, E and Up components of the GPS time series in the Indian reference frame along with the displacement components derived from a global hydrological model. Right panel in each case shows the residual time series after subtracting the contribution of the hydrological, atmospheric and non-tidal ocean load. Dotted curve in the right panel shows the simulated variations due to the Tehri reservoir filling and emptying cycles. Note the anomalous biannual variations in the E component in the right panel.

reservoir impoundment might have locally altered the hydrological conditions (groundwater levels), leading to anomalous variations which may not be modelled using simple poroelastic models which only causes annual variations of the order of $\sim 3 \mathrm{~mm}$ (Gahalaut et al. 2017). Unfortunately, the availability of just one site in the region and a lack of constraints on a more detailed local hydrological response model, limits our ability to explore this further. Ongoing work exploring time series of Sentinel-1 InSAR measurements may shed more light on the nature of this anomalous deformation pattern.

\section{Concluding discussion}

We report anomalous transient deformation in GPS measurements due to earthquake and surface reservoir loading at two sites. At both of these sites the secular motion exhibits an expected trend, specifically site responding to the transient deformation for 50-60 days after the 2015 Gorkha earthquake, show no significant motion (in Indian reference frame) afterwards. Also, the coseismic offsets at these sites due to the 2015 Gorkha earthquake are consistent with the rupture models (Yadav et al. 2017). Similarly, the secular motion at KUNR is also consistent with the locking of the underneath main
Himalayan thrust. These observations attest that the GPS monuments and measurements at these sites are reliable even though some of them are located in the Indo-Gangetic plains. The reported abnormal transients at these sites are due to dynamic or transient loading or due to the local response of the ground to the loading. As is true with all natural events, their actual response cannot be recreated so that we could get more data at other locations also. Thus, in most cases, we work with the limited data, recorded during the event, which is also the case in this article. Furthermore, it is not necessary that all sites exhibit anomalous motion, e.g., only PTNA exhibited anomalous motion in response to the postseismic deformation of the 2015 earthquake and only KUNR, out of several other sites in the region and elsewhere close to the reservoirs (Dumka et al. 2018; Gahalaut et al. 2018), exhibited anomalous response to the reservoir load. Incidence of such anomalous observations is rare. We do not know the physical mechanism behind such nonlinear behaviour, but it is important to document it so that these observations are available for future scrutiny and for the formulation of physical mechanism explaining them.

The 2015 Gorkha earthquake caused anomalous ground displacement in the following 50-60 days at a single GPS site PTNA, located about $250 \mathrm{~km}$ south of the epicentre in the Indo-Gangetic plains. We propose that the moderate shaking of the 2015 
Gorkha earthquake caused slow and permanent deformation in the water-saturated alluvial plains, which continued for nearly 2 months near PTNA.

The Tehri reservoir filling and emptying cycles caused anomalous ground displacement at a single nearby GPS site KUNR. We suggest that the cyclic and annual surface loading of the Tehri reservoir impoundment may have altered the local hydrological conditions leading to anomalous deformation that causes the observed biannual variations in the $\mathrm{E}$ component of the GPS measurements at KUNR.

\section{Acknowledgements}

We thank the Ministry of Earth Sciences, Government of India for the financial support in maintaining GPS stations in the Garhwal Kumaun Himalaya and in the Indo-Gangetic plains. We thank the anonymous reviewer for very helpful comments.

\section{References}

Ader T, Avouac J P, Zeng J L, Lyon-Caen H, Bollinger L, Galetzka J, Genrich J, Thomas M, Chanard K, Sapkota S N, Raujari S, Shrestha P, Ding L and Flouzat M 2012 Convergence rate across the Nepal Himalaya and interseismic decoupling on the main Himalayan thrust: Implications for seismic hazard; J. Geophys. Res. 117 B044403.

Altamimi Z, Collilieux X and Metivier L 2011 ITRF2008: An improved solution of the international terrestrial reference frame; J. Geodyn., https://doi.org/10.1007/s00190-0110444-4.

Dumka R, Choudhury P, Gahalaut V K, Gahalaut K and Yadav R K 2018 GPS measurements of deformation caused by seasonal filling and emptying cycles of four hydroelectric reservoirs in India; Bull. Seismol. Soc. Am., https://doi. org $/ 10.1785 / 0120170355$.

Gahalaut V K, Yadav R K, Sreejith K M, Gahalaut K, Bürgmann R, Agrawal R, Sati S P and Kumar A 2017 InSAR and GPS measurements of crustal deformation due to seasonal loading of Tehri reservoir in Garhwal Himalaya, India; Geophys. J. Int., https://doi.org/10.1093/gji/ggx015.

Gahalaut V K, Gahalaut K, Catherine J K, Sreejith K M, Agrawal R, Yadav R K, Mohanalakshmi C, Naidu M S and Rajeshwar Rao V 2018 Geodetic constraints on tectonic and anthropogenic deformation and seismogenesis of KoynaWarna region, India; Bull. Seismol. Soc. Am., https://doi. org/10.1785/0120170373.

Herring T A 2005 GLOBK, Global Kalman filter VLBI and GPS analysis program, version 10.2; Report, Mass. Inst. of Technol., Cambridge, MA.

Hough S E, Martin S S, Gahalaut V, Joshi A, Landes M and Bossu R 2016 A comparison of observed and predicted ground motions from the $2015 M_{\mathrm{w}} 7.8$ Gorkha, Nepal, earthquake; Nat. Hazards, https://doi.org/10.1007/s11069016-2505-8.

King R W and Bock Y 2005 Documentation of the GAMIT GPS analysis software release 10.2; Report, Mass. Inst. of Technol., Cambridge, MA.

Martin S M, Hough S E and Hung C 2015 Ground motions from the $2015 M_{\mathrm{w}} 7.8$ Gorkha, Nepal, earthquake constrained by a detailed assessment of macroseismic data; Seismol. Res. Lett. 86 1524-1532, https://doi.org/10.1785/ 0220150138.

Rajendran C P, John B, Rajendran K and Sanwal J 2016 Liquefaction record of the great 1934 earthquake predecessors from the north Bihar alluvial plains of India; J. Seismol. 20 733-745.

Yadav R K, Roy P N S, Gupta S K, Khan P K, Catherine J K, Prajapati S K, Kumar A, Puviarasan N, Bhu H, Devachandra M, Malik J, Kundu B, Debbarma C and Gahalaut V K 2017 Rupture model of $M_{\mathrm{w}} 7.82015$ Gorkha, Nepal earthquake: Constraints from GPS measurements of coseismic offsets; J. Asian Earth Sci. 133 $56-61$.

Yadav R K, Gahalaut V K, Kumar A, Sati S P, Catherine J, Gautam P, Kumar K and Rana N 2019 Strong seismic coupling underneath Garhwal-Kumaun region, NW Himalaya, India; Earth Planet. Sci. Lett. 506 8-14.

Zhao B, Bürgmann R, Wang D, Tan K, Du R and Zhang R 2017 Dominant controls of downdip afterslip and viscous relaxation on the postseismic displacements following the $M_{\mathrm{w}} 7.9$ Gorkha, Nepal, earthquake; J. Geophys. Res.: Solid Earth 122 8376-8401, https://doi.org/10.1002/2017JB01 4366 . 